\title{
Parasites pitched against nature: Pitch Lake water protects guppies (Poecilia reticulata) from microbial and gyrodactylid infections
}

\author{
BETTINA SCHELKLE ${ }^{1}$, RYAN S. MOHAMMED ${ }^{2}$, MICHAEL P. COOGAN ${ }^{3}$, \\ MARK MCMULLAN ${ }^{4}$, EMMA L. GILLINGHAM ${ }^{1}$, COCK VAN OOSTERHOUT ${ }^{4}$ \\ and $\mathrm{JOANNE} \mathrm{CABLE}{ }^{1} *$ \\ ${ }^{1}$ School of Biosciences, Cardiff University, Cardiff CF10 3AX, UK \\ ${ }^{2}$ Department of Life Sciences, University of the West Indies, St Augustine, Trinidad, West Indies \\ ${ }^{3}$ School of Chemistry, Cardiff University, Cardiff CF10 3AT, UK \\ ${ }^{4}$ School of Environmental Sciences, University of East Anglia, Norwich Research Park, Norwich NR4 7TF, UK
}

(Received 23 April 2012; revised 18 May 2012; accepted 21 May 2012; first published online 26 Fuly 2012)

SUMMARY

The enemy release hypothesis proposes that in parasite depleted habitats, populations will experience relaxed selection and become more susceptible (or less tolerant) to pathogenic infections. Here, we focus on a population of guppies (Poecilia reticulata) that are found in an extreme environment (the Pitch Lake, Trinidad) and examine whether this habitat represents a refuge from parasites. We investigated the efficacy of pitch in preventing microbial infections in Pitch Lake guppies, by exposing them to dechlorinated water, and reducing gyrodactylid infections on non-Pitch Lake guppies by transferring them to Pitch Lake water. We show that (i) natural prevalence of ectoparasites in the Pitch Lake is low compared to reference populations, (ii) Pitch Lake guppies transferred into aquarium water develop microbial infections, and (iii) experimentally infected guppies are cured of their gyrodactylid infections both by natural Pitch Lake water and by dechlorinated water containing solid pitch. These results indicate a role for Pitch Lake water in the defence of guppies from their parasites and suggest that Pitch Lake guppies might have undergone enemy release in this extreme environment. The Pitch Lake provides an ideal ecosystem for studies on immune gene evolution in the absence of parasites and long-term evolutionary implications of hydrocarbon pollution for vertebrates.

Key words: antihelminthic, asphalt, Pitch Lake, Gyrodactylus, Poecilia reticulata, enemy release.

\section{INTRODUCTION}

Host parasite co-evolution acts to maintain polymorphism and/or increase the rate of molecular evolution (Lively, 1987; Dybdahl and Lively, 1998; Lively and Jokela, 2002; Decaestecker et al. 2007; Woolhouse et al. 2002; Paterson et al. 2010). With the majority of all free-living animals hosting at least 1 parasite taxon (Price, 1980), populations without parasites represent a rare opportunity to understand the effects of host-parasite co-evolution. Island populations may experience reduced selection pressures due to decreased parasite diversity, prevalence and intensity (e.g. Lindström et al. 2004), similar to invasive species that are released from their natural enemies in novel environments (Liu and Stiling, 2006). A special case of 'enemy release' may be experienced by populations in extreme environments in which hosts may find refuge from their parasites (Tobler et al. 2007). The adaptive forces in these hostile habitats are often well defined (Amils Pibernat

* Corresponding author: School of Biosciences, Cardiff University, Cardiff CF10 3AX, UK. Tel: ++44(0) 2029876022 . Fax: $\quad+44(0) 2920874116$. E-mail: cablej@cardiff.ac.uk et al. 2007), yet, their effects on parasites infecting hosts inhabiting such environments are rarely assessed, even though they can have a major impact on the host-parasite relationships. Populations of guppies with little or no parasites are rare (see Fraser and Neff, 2010), but preliminary investigations indicate that the Pitch Lake may be one such habitat (Cable, 2011).

The Pitch Lake (Fig. 1) consists of a natural upwelling of oils that contain hydrocarbons, sulphur, metals and volcanic ash at concentrations usually considered toxic to living organisms (Peckham, 1895; Ponnamperuna and Pering, 1967; Burgess et al. 2005; World Health Organization Concise International Chemical Assessment Document, 2005; Marković et al. 2007). It is the largest asphalt lake in the world (ca. $0.8 \mathrm{~km}^{2}$ ), resembling a volcano crater, located on the south west coast of Trinidad. Only 4 other asphalt lakes exist worldwide: the La Brea tar pits, the McKittrick tar pits, Carpinteria tar pits (all 3 in California, USA) and Lake Guanoco (Venezuela). Although such lakes have been the focus of many paleoecological studies (e.g. Coltrain et al. 2004), little is published on their extant biodiversity (Kadavy et al. 1999; Ali et al.2006; 


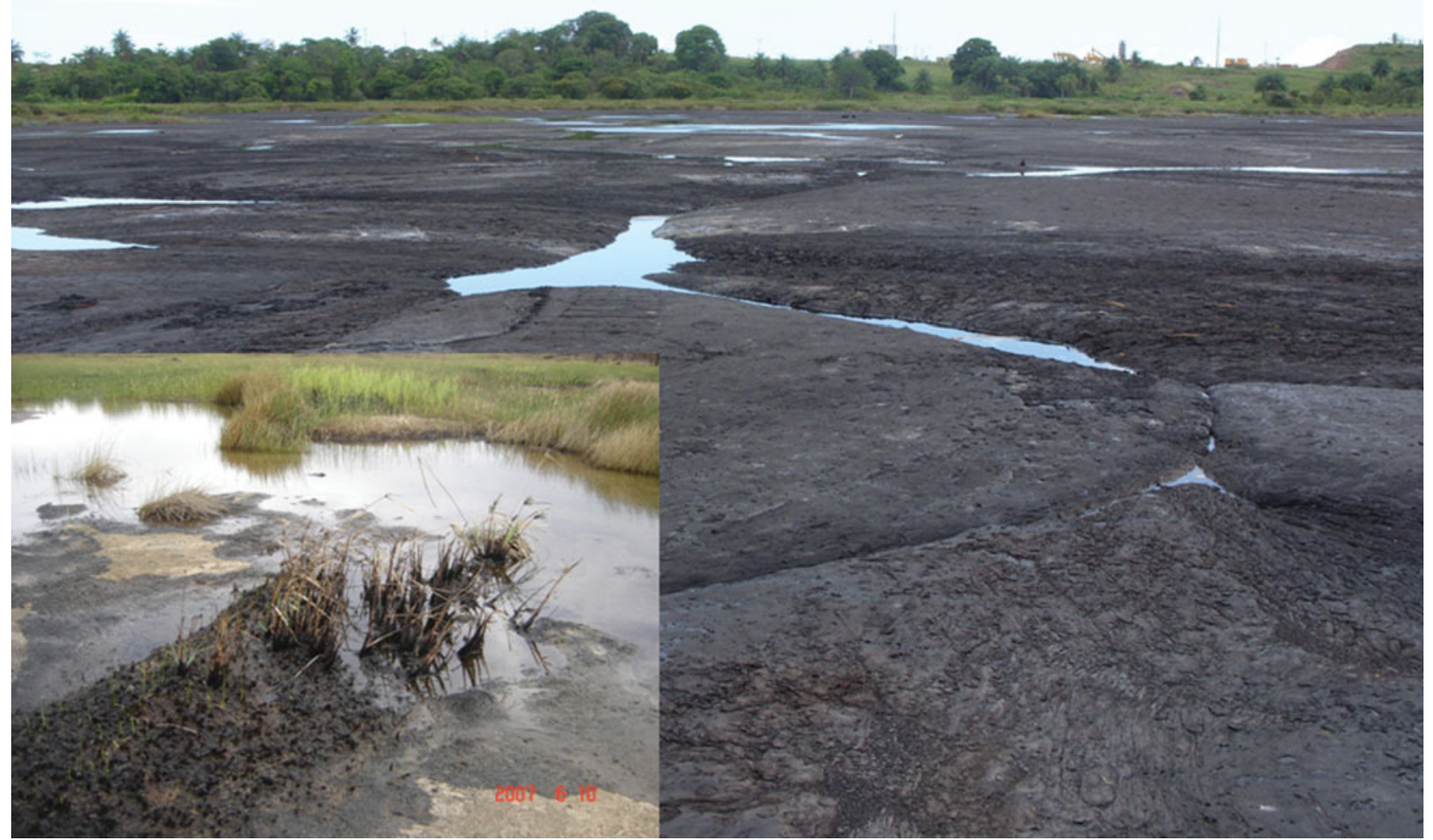

Fig. 1. The Pitch Lake, Trinidad. Insert: a close-up on one of the pools where guppies were collected for this study.

Schulze-Makuch et al. 2010) or on the evolution of species in this habitat (but see Tezuka et al. 2011). Despite its hostile environment, freshwater pools amongst the pitch folds of the encrusted Pitch Lake surface are a habitat for plants (e.g. Nymphaea and Nitella; personal observations), bacteria (e.g. Pseudomonas; see Ali et al. 2006; Schulze-Makuch et al. 2010), invertebrates (e.g. dragon fly larvae, aquatic beetles; personal observations), the amphibian Pseudis paradoxa (personal observations) and fish (e.g. Poecilia reticulata, Rivulus hartii, see Burgess et al. 2005; and Polycentrus schomburgkii, personal observations).

The guppy (Poecilia reticulata), a small, hardy freshwater fish, is found throughout Trinidad and Tobago as well as in Venezuela, Guyana and Surinam (Magurran, 2005). Throughout their natural habitat, guppies are parasitized by the ectoparasitic, hermaphroditic gyrodactylids (for exceptions, see Martin and Johnson, 2007; Fraser and Neff, 2010). Despite being helminths, Gyrodactylus species are regarded as microparasites (Scott and Anderson, 1984) due to their multi-modal, hyperviviparous reproductive system (Cable and Harris, 2002; Bakke et al. 2007). In natural populations of guppies, gyrodactylids often occur at prevalences of up to 75\% (van Oosterhout et al. 2007). Such high parasite occurrence is mainly characteristic of lowland guppy populations, whereas the Trinidadian upland populations are occasionally free of gyrodactylids (Martin and Johnson, 2007; Fraser and Neff, 2010). The difference in gyrodactylid load may be explained by the fact that upland host populations are relatively small in census population size and have arisen from founder events, whilst being connected by a very limited amount of upstream migration (Barson et al. 2009). Furthermore, given that parasitized guppies are more likely to be flushed downstream (van Oosterhout et al. 2007) some upland populations appear to be parasite-free, either due to failure of parasite establishment or subsequent parasite population extinction. Hence, the guppies in some upland populations such as the Upper Naranjo have been shown to be devoid of gyrodactylids for almost a decade (personal observations) and can be regarded as naive to these parasites.

In the present study, we compare parasite burdens in the field with published data and assess the importance of the pitch environment for the health of guppies using experimentally infected fish. In Part 1, parasite infections are assessed for the Pitch Lake guppy population. Having confirmed the absence of Gyrodactylus spp. in the Pitch Lake, we hypothesized 
Table 1. Minimum and maximum water physico-chemistry values of the Pitch Lake and three riverine sites in Trinidad recorded in different seasons between 2003 and 2012

\begin{tabular}{|c|c|c|c|c|}
\hline & Pitch Lake & Upper Naranjo & Mid Naranjo & Lower Aripo \\
\hline $\mathrm{pH}$ & $2 \cdot 8-8 \cdot 4$ & $7 \cdot 6-9 \cdot 35$ & $7 \cdot 4-7 \cdot 6$ & $7 \cdot 1-8 \cdot 8$ \\
\hline Temperature ${ }^{\circ} \mathrm{C}$ & $26 \cdot 1-32 \cdot 5$ & $23 \cdot 1-25 \cdot 4$ & $23 \cdot 0-23 \cdot 4$ & $23 \cdot 7-25 \cdot 9$ \\
\hline Salinity $\mathrm{gL}^{-1}$ & $0 \cdot 1-0 \cdot 7$ & $0 \cdot 1-0 \cdot 2$ & $0 \cdot 1$ & $0 \cdot 0-0 \cdot 2$ \\
\hline Conductivity $\mu \mathrm{S}$ & $404-1649$ & $120-402 \cdot 5$ & $210-235$ & $232-328$ \\
\hline Dissolved oxygen $\mathrm{mgL}^{-1}$ & $0 \cdot 7-2 \cdot 32$ & $5 \cdot 42-7 \cdot 8$ & $5 \cdot 15-8 \cdot 99$ & $2 \cdot 1-8 \cdot 77$ \\
\hline
\end{tabular}

that Pitch Lake water had significant anti-parasitic properties. Therefore, in Part 2, we experimentally investigated the effect of Pitch Lake water on fungal and/or bacterial (from hereon: microbial) and helminth infections in guppies. Firstly, we exposed Pitch Lake guppies to aquarium water and Gyrodactylus bullatarudis infected fish to Pitch Lake water. Secondly, we directly exposed G. turnbulli infected, ornamental guppies to dechlorinated aquarium water containing solid pitch or to artificially produced pitch water of varying ages. By producing pitch water of varying ages, we also tested whether the antihelminthic compounds are chemically unstable or volatile to provide an overview of the anti-parasitic properties of Pitch Lake water.

\section{MATERIALS AND METHODS}

This study was approved by the Cardiff University Animal Ethics Committee and regulated by a UK Home Office licence (PPL 30/2357).

\section{Sampling sites}

Guppies (SL: 9·1-22.4 mm) were collected from the Pitch Lake (grid reference UTM 20P: 650341.45 E, 1131668.93 N; Fig. 1) in 2004 and 2006-2008, and from the Upper Naranjo in 2008. Pitch Lake pools in which fish were caught varied widely in their water physio-chemistry $(\mathrm{pH}$, temperature, salinity, dissolved oxygen and conductivity measured with an YSI pH 100 and YSI 85 Multi Probe) and differ from 3 riverine reference sampling sites (Table 1).

For the parasite prevalence analysis on Pitch Lake guppies (Part 1), variable numbers of live fish $(n)$ collected in randomly chosen pools in February 2004 $(n=64)$, June $2006(n=54)$ and June $2007(n=25)$ were euthanized on site with an overdose $(0 \cdot 04 \%)$ of MS222 and individually stored in $1.5 \mathrm{ml}$ Eppendorf tubes containing $90 \%$ ethanol. In total, 5 representative pools of varying sizes were sampled, all of which contained guppies and which were spread across the lake. For Transfer Experiment 1 (Part 2), pitch water and live guppies were collected at the Pitch Lake in June $2008(n=10)$ and transported to the laboratory in Trinidad. The guppies originated from different pools that were all interconnected. A control sample of guppies $(n=10)$ for Experiment 1 plus 20 guppies for Experiment 2 (Part 2) were collected from the Upper Naranjo (UTM 20P: 692498.44 E, $118257.53 \mathrm{~N}$ ), a tributary of the Aripo River that originates in the Northern mountain range of Trinidad and flows into the Caroni drainage.

\section{Part 1: Natural parasite fauna}

For the parasite analysis of Pitch Lake guppies, samples from 2004, 2006 and 2007 were analysed for gyrodactylid prevalence, mean intensity and range. The preserved fish were transferred to a Petri dish and completely immersed in ethanol. Using a dissecting microscope the surface of the fish was scanned and any parasites recorded. The ethanol in which the fish had been originally fixed was also screened for any dislodged parasites. Gyrodactylid parasites were removed from their host using insect pins and transferred onto a microscope slide. Specimens were mounted in ammonium picrate glycerine after partial digestion (Harris et al. 1999) and examined for differences in haptor morphology to identify worms to species level.

\section{Part 2: Experimental transfer}

To monitor gyrodactylid infections in Experiments 1 and 2 guppies were anaesthetized with $0 \cdot 02 \%$ MS222 and their sex and standard length were recorded. Fish were screened for external parasites using a fibreoptic light and a stereo-microscope according to the methods described by Schelkle et al. (2009). Fish were maintained individually in $1 \mathrm{~L}$ pots throughout the duration of the experiment and were fed on Aquarian ${ }^{\circledR}$ fish flakes once daily. Additionally, uninfected fish were exposed to the same treatments in both experiments as mortality controls. For routine maintenance, fish and parasite cultures were kept at $25 \pm 1^{\circ} \mathrm{C}$, a $12 \mathrm{~h}$ light : $12 \mathrm{~h}$ dark cycle and guppies were fed at least once daily with Aquarian ${ }^{\circledR}$ fish flakes.

In Experiment 1, we examined (a) the effect of replacing Pitch Lake water with dechlorinated aquarium water on the health of Pitch Lake guppies and (b) the effect of original Pitch Lake water on the mean intensity of $G$. bullatarudis parasites (isolated from Lower Aripo guppies; Cable and 
van Oosterhout, 2007) on guppies originating from the Upper Naranjo. To test the former, 10 guppies from the Pitch Lake (with no gyrodactylid infection) were removed from the original Pitch Lake water and then they were kept in aquarium water and maintained individually over 8 days. After 4 days of acclimatization, fish were screened for signs of microbial infection daily until the experiment finished on Day 8. Controls originating from the Pitch Lake $(n=10)$ were maintained for the same period in the original pitch water. To examine the effect of Pitch Lake water on the presence of gyrodactylid parasites, wild, naive guppies from the Upper Naranjo were exposed to infected conspecifics from the Lower Aripo to acquire $G$. bullatarudis infections naturally (mean \pm s.E. $11.9 \pm 1$ parasites per fish). Infected fish $(n=10)$ were then exposed to $25 \%$ original pitch water collected at the Pitch Lake and diluted with dechlorinated aquarium water. After $48 \mathrm{~h}$, the Pitch Lake water concentration was raised to $50 \%$ and maintained at this concentration until the end of the experiment. The stepped increase in Pitch Lake water concentration allowed the fish to acclimatize and prevent osmotic problems. Uninfected and infected control guppies ( $n=10$ each) were maintained in dechlorinated water. For Experiment 1 , pitch water was used within $24 \mathrm{~h}$ of collection and trials were carried out at $21 \pm 2{ }^{\circ} \mathrm{C}$.

Experiment 2 tested the efficacy of pitch and pitch water preparations against G. turnbulli (Gt3, isolated from pet shop guppies in 1997; see van Oosterhout et al. 2003) infections on ornamental guppies (total $n=84$ ), acquired through exposure to infected conspecifics. Parasite loads on guppies were assessed by screening fish before and after the 8-day treatment period. The Pitch Lake water and pitch were collected in June 2009. In total, there were 5 treatments: (a) solid pitch, (b) fresh pitch water, (c) old pitch water, (d) ancient pitch water, and (e) aquarium water as a control. Pitch water was prepared from solid pitch and dechlorinated aquarium water 1-3 months after the field collection of pitch. Pitch was added to the bottom of a $1 \mathrm{~L}$ pot containing $250 \mathrm{ml}$ of dechlorinated water for the pitch treatment $(32.5 \mathrm{~g}$ was regarded as safe for guppies after preliminary trials, and was moulded to a thickness of $0.5 \mathrm{~cm}$ to increase surface area: ca. $173 \mathrm{~cm}^{2}$ ). For the 3 pitch water treatments, the pitch was removed from the water after $24 \mathrm{~h}$. Fresh pitch water was used directly after pitch removal, whereas old and ancient pitch water was left to stand for 41 and 82 days, respectively, at $15-25^{\circ} \mathrm{C}$. These aged pitch water preparations resulted in the loss of unstable and volatile compounds narrowing down the possible chemical characteristics of the active compound before starting spectroscopic analyses, which were used to confirm the presence of volatile and/or unstable compounds. To identify any complex organic species which may be present in pitch and responsible for the observed anti-parasitic properties, proton and carbon Nuclear Magnetic Resonance (NMR) spectra were measured (Bruker Avance, 250, recording at ${ }^{1} \mathrm{H} 250 \mathrm{MHz} ; 62.5 \mathrm{MHz}$ ${ }^{13} \mathrm{C}, 5 \mathrm{~mm}$ tube) on extracts of pitch samples, using deuterium oxide (heavy water, $\mathrm{D}_{2} \mathrm{O}$ ) and deuterated chloroform $\left(\mathrm{CDCl}_{3}\right)$ as extractants. Additionally, Infra Red (IR) spectra (Jasco 380, thin film) were analysed to identify organic functional groups.

Since not all fish were tested at the same time, the solid pitch treatment method was used in 2 small experiments before and after the main study to confirm that pitch efficacy against gyrodactylids remained constant throughout the experimental period despite the storage of pitch in plastic containers between individual sets of tests. Naive fish from a 10 -year-old inbred stock were infected by exposing individual fish to an infected donor for 3-4 days. For every set of tests, near equal numbers of replicates (15 \pm 3 per treatment) were tested at $25 \pm 1{ }^{\circ} \mathrm{C}$, with fish containers randomly placed within the experimental laboratory space including 27 control treatments.

\section{Statistical analyses}

Differences in the frequency of microbial infections and mortalities in Pitch Lake guppies exposed to aquarium water compared to their counterparts in Pitch Lake water (Experiment 1) were confirmed using a Fisher's Exact Test. The infection trajectories for Experiment 2 were assessed using a General Linear Mixed Model (GLMM). Treatment (pitch or aquarium water) and time were included in the model as independent variables with animal ID as random effect factor.

As a measure of efficacy of solid pitch and artificial pitch water treatments in Experiment 2 the relative decrease in parasite load $\left(\Delta E_{t}\right)$ was calculated to account for the initial variation in parasite loads between fish as well as the repeated measurement of parasite load before and after treatment on the same individual:

$\Delta E_{t}=\left(L_{0}-L_{t}\right) / L_{0}$, for $L_{t}<L_{0}$, and

$\Delta E_{t}=0$ for $L_{t} \geqslant L_{0}$,

where $L_{0}$ is the initial parasite burden at day 0 and $L_{t}$ is the parasite burden at day $t$ (Schelkle et al. 2010). When parasite load increased rather than decreased, the treatment was not efficient and was defined as $\Delta E_{t}=0$.

A Generalized Linear Model (GLM) fitted with a quasibinomial error distribution and a logit link function was conducted to assess differences in efficacy with treatment, fish sex and standard length as independent variables plus a fish sex*standard length interaction. Standardized residuals for all models were assessed using a Shapiro-Wilk test 


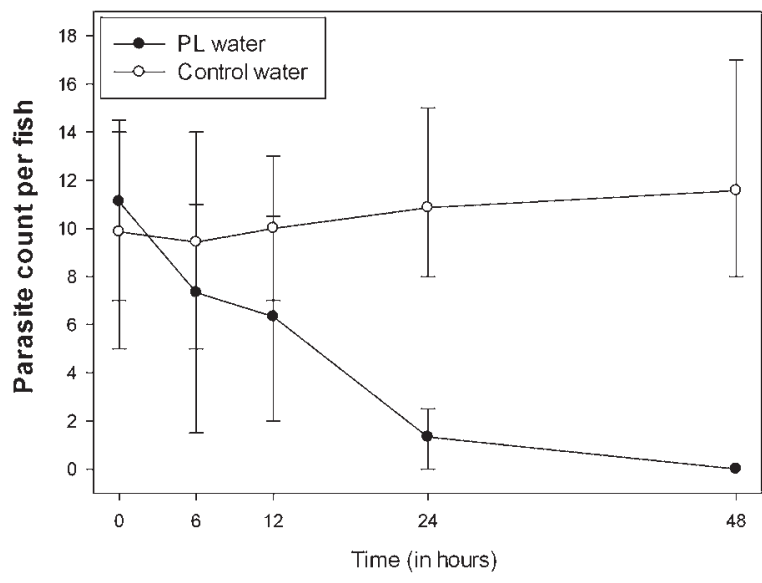

Fig. 2. Gyrodactylus bullatarudis parasite load ( \pm s.E.) on guppies (Poecilia reticulata) originating from the Upper Naranjo river exposed to original Pitch Lake (PL) water diluted to $25 \%$ up to $12 \mathrm{~h}$ and $50 \%$ between 12 and $48 \mathrm{~h}$ (closed circles) or dechlorinated aquarium water (open circles) over time. $N=10$ for each treatment.

additionally to visual examination of histograms and normality plots, and both random and fixed model terms were reduced using stepwise deletions based on the Log-Likelihood method with $\alpha=0 \cdot 05$. All data were analysed in $\mathrm{R}$ v. 2.9.2 (R Development Core Team, 2011).

\section{RESULTS}

\section{Part 1: Natural parasite fauna}

No helminth infections were found on the guppies sampled from the Pitch Lake population $(n=143)$, with the exception of 3 worms recovered on 3 individual fish in 2004 belonging to a newly described genus of the Gyrodactylidae, Ieredactylus rivulus (Schelkle et al. 2011), a parasite usually found on Rivulus hartii.

\section{Part 2: Experimental transfer}

Exposure of Pitch Lake guppies to aquarium water led to a $66.7 \%$ increase in unspecified microbial infections. As a result, 7 out of 10 Pitch Lake fish were infected or died from the infection in aquarium water, compared to 1 out of 10 in the control with original Pitch Lake water (Fisher's Exact 'Test: $P=0 \cdot 01)$. The symptoms were consistent with fin rot and cotton-like growth characteristic of opportunistic Saprolegnia and Flavobacterium spp. infections. No further analyses were conducted to identify the specific infections.

When experimentally infected guppies from the Upper Naranjo were exposed to original Pitch Lake water they lost all their gyrodactylid parasites within $48 \mathrm{~h}$ of exposure, whereas the parasite population on fish in aquarium water remained stable (GLMM:

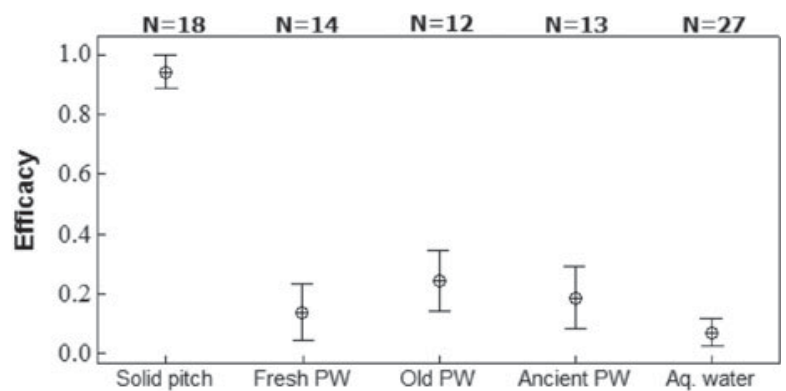

Fig. 3. Mean efficacy ( \pm s.E.) of solid pitch, fresh pitch water $(\mathrm{PW})$, old pitch water, ancient pitch water and aquarium (aq.) water against Gyrodactylus turnbulli infections in ornamental strain guppies (Poecilia reticulata $)$. Efficacy $\left(\Delta E_{t}=\left(L_{0}-L_{t}\right) / L_{0}\right.$, for $L_{t}<L_{0}$, and $\Delta E_{t}=0$ for $\left.L_{t} \geqslant L_{0}\right): 1=$ effective; $0=$ not effective. $N=$ number of replicates.

treatment $\mathrm{t}=4.017, \quad$ D.F. $=18, \quad P<0.001 ; \quad$ time $\mathrm{t}=-5 \cdot 080$, D.F. $=71, P<0 \cdot 001$; Fig. 2).

In Experiment 2, the only treatment that was effective in removing parasites was the solid pitch in water treatment $(94 \cdot 4 \%$ efficacy), whereas the efficacies of fresh $(14 \cdot 1 \%)$, old $(24 \cdot 7 \%)$ and ancient $(19 \%)$ pitch water treatments were not significantly different from the control $(7 \cdot 3 \%)$ (GLM: treatment

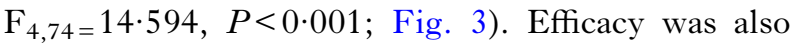
influenced by a fish sex*standard length interaction: efficacy increases with decreasing size in adult fish, but is constant in juveniles (GLM: fish sex*standard length $\left.\mathrm{F}_{2,74}=3 \cdot 966, P=0 \cdot 023\right)$.

Spectroscopic analysis (proton ${ }^{1} \mathrm{H}$ and carbon ${ }^{13} \mathrm{C}$ Nuclear Magnetic Resonance, Infrared) indicated that while the majority of the pitch consists of simple hydrocarbons which did not transfer to the water phase, there were signals indicative of the presence of aromatic, phenolic and ketonic species, and trapped methane gas (Table 2). These were only observed following extraction into organic solvent $\left(\mathrm{CDCl}_{3}\right)$ with the levels of any species extracted into $\mathrm{D}_{2} \mathrm{O}$ below the detection limits of the techniques by attempting to mimic the pitch water experiments.

\section{DISCUSSION}

The water in the Pitch Lake in Trinidad is dominated by simple linear and branched hydrocarbons, and displays extreme chemical properties. Yet, it supports 3 species of freshwater fish (Poecilia reticulata, Rivulus hartii and Polycentrus schomburgkii). We found that Pitch Lake guppies are not naturally infected with Gyrodactylus species (Part 1) and that gyrodactylid-infected control guppies lose their infections when transferred to Pitch Lake water (Part 2). Furthermore, Pitch Lake fish that are removed from Pitch Lake water rapidly develop microbial infections (Part 2).

Gyrodactylus species are highly prevalent in natural populations of guppies (Martin and Johnson, 2007; 
Table 2. Chemicals and their suggested assignments based on the molecule's functional group from spectroscopic analysis (proton and carbon nuclear magnetic resonance: ${ }^{1} \mathrm{H}$ and ${ }^{13} \mathrm{C} \mathrm{NMR}$, respectively; infrared: IR) of pitch

\begin{tabular}{|c|c|c|c|}
\hline $\begin{array}{l}\text { Position of } \\
\text { band (ppm) }\end{array}$ & Peak shape & $\begin{array}{l}\text { Relative } \\
\text { intensity }\end{array}$ & $\begin{array}{l}\text { Chemical compound ( Suggested assignment to } \\
\text { likely pitch components) }\end{array}$ \\
\hline \multicolumn{4}{|l|}{${ }^{1} \mathbf{H} \mathbf{N M R}$} \\
\hline$-0 \cdot 9-0 \cdot 8$ & Broad & Medium & Methane (trapped methane gas) \\
\hline $0 \cdot 5-1 \cdot 5$ & Broad, featureless & Very strong & $\begin{array}{l}\text { Hydrocarbon methylene (simple hydrocarbons, hydrocarbon } \\
\text { side-chains of substituted aromatics) }\end{array}$ \\
\hline $2 \cdot 0-2 \cdot 5$ & $\begin{array}{l}\text { Broad, multiple } \\
\text { maxima }\end{array}$ & Weak & $\begin{array}{l}\text { methyl/methylene } \alpha \text { to aryl, vinyl, carbonyls. (methyl and } \\
\text { polymethyl aromatics and polyaromatic hydrocarbons, } \\
\text { unsaturated hydrocarbons, ketonic hydrocarbons, } \\
\text { carboxylic acids) }\end{array}$ \\
\hline $6 \cdot 6-7 \cdot 9$ & $\begin{array}{l}\text { Broad, multiple } \\
\text { maxima }\end{array}$ & Weak & $\begin{array}{l}\text { Aromatic/heteroaromatic (benzene, poly aromatic } \\
\text { hydrocarbons, sulphur, oxygen and nitrogen heterocycles) }\end{array}$ \\
\hline $10 \cdot 5$ (centre) & Very broad & Weak & $\begin{array}{l}\text { Phenol hydroxyl/Carboxylic acid (phenols, cresols and } \\
\text { phenolic heterocycles, long-chain carboxylic acids) }\end{array}$ \\
\hline \multicolumn{4}{|l|}{${ }^{13} \mathrm{C}$ NMR } \\
\hline $29 \cdot 7$ & Broad & Strong & Hydrocarbon methylene (simple hydrocarbons) \\
\hline-4 (centre) & Very broad & Weak & Methane (trapped methane gas) \\
\hline \multicolumn{4}{|l|}{ IR } \\
\hline 3696 & Sharp & Weak & 'Free' (non-H-bonded) O-H phenols, phenolic heterocycles) \\
\hline 3619 & Sharp & Weak & 'Free' (non-H-bonded) O-H (phenols, phenolic heterocycles) \\
\hline 3403 & Broad & Weak & Carboxylic O-H (long chain carboxylic acids) \\
\hline 2925 & Broad & Very strong & $\begin{array}{l}\text { Hydrocarbon } \mathrm{C}-\mathrm{H} \text { (simple hydrocarbons, hydrocarbon } \\
\text { side-chains of substituted aromatics) }\end{array}$ \\
\hline 2855 & Broad & Very strong & $\begin{array}{l}\text { Hydrocarbon } \mathrm{C}-\mathrm{H} \text { (simple hydrocarbons, hydrocarbon } \\
\text { side-chains of substituted aromatics) }\end{array}$ \\
\hline 1707 & Sharp & Medium & Ketone (aliphatic ketones in long chain simple hydrocarbon) \\
\hline 1607 & Broad & Strong & $\begin{array}{l}\text { Aromatic } \mathrm{C}-\mathrm{C} \text { (benzene, poly aromatic hydrocarbons, sulphur, } \\
\text { oxygen and nitrogen heterocycles) }\end{array}$ \\
\hline 1457 & Broad & Medium & $\begin{array}{l}\text { Hydrocarbon C-C (simple hydrocarbons, hydrocarbon side-chains } \\
\text { of substituted aromatics) }\end{array}$ \\
\hline 1376 & Broad & Medium & $\begin{array}{l}\text { Hydrocarbon C-C (simple hydrocarbons, hydrocarbon side-chains } \\
\text { of substituted aromatics) }\end{array}$ \\
\hline
\end{tabular}

van Oosterhout et al. 2007; Fraser and Neff, 2010) making the observation of their absence in the Pitch Lake population unusual, particularly since hydrocarbons have been associated with an increase of gyrodactylids on infected fish (Kahn and Kiceniuk, 1988; Khan, 1990). In addition, we did not detect any internal macroparasites in a sample of 25 guppies from Pitch Lake (McMullan, 2010). However, a previously unknown monogenean genus, Ieredactylus, was found which only occurs on guppies in the Pitch Lake (Schelkle et al. 2011). Ieredactylus rivulus normally infects Hart's Rivulus, a fish that can migrate over land; hence, the parasite is thought to be hardy and robust (Schelkle et al. 2011).

The extreme conditions in the Pitch Lake habitat may act as a defence for guppies against gyrodactylid and microbial infections originating from outside the Pitch Lake region. The isolation and genetic divergence of Pitch Lake guppies (Willing et al. 2010) indicates that this asphalt lake may act as a refuge, similar to the limestone caves in Mexico which are thought to be a refuge from parasites for Atlantic mollies (P. mexicana, see Tobler et al. 2007). Such low parasite prevalence within guppy populations elsewhere in Trinidad has only been observed in small, relatively isolated upland populations (Martin and Johnson, 2007; Fraser and Neff, 2010). Possibly, the physical isolation in combination with the small population size could also have contributed to the lack of ectoparasites on the Pitch Lake guppies. In addition to this, colonization of the Pitch Lake by gyrodactylids will be severely hindered by the extreme environmental conditions that appear to be lethal, at least to the $G t 3$ strain of these parasites, either through direct exposure to pitch components and/ or indirectly through increased host mucus production causing the parasites to be sloughed off (for review on fish mucus; see Shephard, 1994). Ideally, we would have tested whether Pitch Lake guppies were susceptible to infection with Gyrodactylus spp., but as Pitch Lake fish die in normal aquarium water and gyrodactylids cannot survive in pitch water this was not possible.

In the Pitch Lake, guppy evolution appears to be primarily driven by the harsh environmental conditions. Although some dead guppies were observed in the pools with extreme $\mathrm{pH}(2 \cdot 8$ and $8 \cdot 4 ; c f$. Dunson et al. 1997), Pitch Lake guppies are adapted to this environment. Studies on the Major Histocompatibility Complex (MHC), a multigene 
family associated with immune functioning in vertebrates, show that the MHC polymorphism is low but remarkably diverged in the Pitch Lake guppy population compared to other Trinidadian guppy populations (McMullan, 2010). A low MHC variation could account for the increased pathogen susceptibility of these fish when in aquarium water (6 out of 7 guppies were infected or dead at the end of the experiment), as could the multitude of mutagenic and teratogenic hydrocarbons in Pitch Lake water that are known to suppress the immune system (World Health Organization Concise International Chemical Assessment Document, 2005). We cannot rule out though that potential stress associated with changes in the water physio-chemistry caused chronic endemic infection in the guppies to become acute or opportunistic pathogens in the water to infect fish. However, an argument against this is that to maintain Pitch Lake guppies in the laboratory in dechlorinated aquarium water, they need to be continuously treated with anti-fungal and antibacterial medication (personal observations).

Exposing gyrodactylid infected fish to 'original' Pitch Lake water and solid pitch showed high antiparasitic characteristics of the treatments, but artificial pitch water preparations were not effective in reducing ectoparasite burdens in guppies. This suggests that the anti-parasitic agent(s) within the Pitch Lake are volatile or unstable compound(s), which is supported here by the spectroscopic analyses. Hence, the anti-parasitic pitch properties are probably not associated with simple hydrocarbon toxicity. It seems more likely that an unidentified chemical entity of high specific toxicity is transferred to the water at a concentration below Nuclear Magnetic Resonance detection limits, which is either unstable in water/air or is of low enough molecular mass that it is volatile and lost from the water (Pan and Raftery, 2007). The spectroscopic techniques used in the current study are mostly insensitive to simple inorganic ions, such as sulphides or selenides (Lawrence et al. 2000). However, inorganic compounds such as sulphides or selenides are stable ions, so they can be disregarded as potential anti-parasitic compounds due to its apparent instability or volatility (Lawrence et al. 2000).

The fast degradation of the active compound against parasites might explain the high efficacy of original pitch water and solid pitch against gyrodactylids: original pitch water in the lake is constantly enriched with soluble pitch compounds, so concentrations of unstable/volatile chemicals are likely to reach high levels. Indeed, the dissolved pitch compounds accumulated to a harmful concentration that required dilution for non-Pitch Lake guppies used in Experiment 1 (Part 2). The low efficacy of artificial pitch water preparations implies that water cycling in the Lake, as a consequence of the continual upwelling of fresh pitch (Peckham, 1895;
Ponnamperuma and Pering, 1967), is essential for the enrichment of original pitch water to give it its anti-parasitic properties.

The discovery of a habitat with an apparently low parasite fauna such as the Pitch Lake opens up interesting possibilities for research on host-parasite co-evolution and immunogenetics. By relaxing the parasite selection pressures, the adaptive evolution of the MHC genes is predicted to differ from that in other parasite-rich environments, although confounding effects of the environment (including mutagenic effects and immune-suppressing effects) need to be taken into consideration.

In conclusion, local water chemistry is essential for the survival of Pitch Lake guppies since these fish appear to depend heavily on its anti-parasitic properties. Volatile or unstable compounds derived from pitch might be protecting these guppies from gyrodactylid and microbial infections, thus parasitemediated selection may be relatively relaxed in the Pitch Lake environment. Further detailed analyses on changes in microbial community of pathogens with the corresponding changes in the direction of the evolutionary arms race in host immune genes are warranted to better understand the consequences of oil pollution on the macro-evolution of vertebrates.

\section{ACKNOWLEDGEMENTS}

We thank Sarah Müller and Linda Erlandsson for technical assistance. Financial support was provided by a Biotechnology and Biological Sciences Research Council (BB/D526137/1) CASE Studentship to B.S. and a European Community Framework Programme 6 Marie Curie Host Fellowship for Transfer of Knowledge (MTKD-CT-2005-030018).

\section{REFERENCES}

Ali, D., Haque, S., Ramsubhag, A., Guinan, E. and SchulzeMakuch, D. (2006). Pitch lake, Trinidad: An analog site for hydrocarbon pools on Titan. Astrobiology 6, 176.

Amils Pibernat, R., Ellies-Evans, C. and Hinghofer-Szalkay, H. G. (2007). Life in Extreme Environments. Springer, Dordrecht, The Netherlands. Bakke, T. A., Cable, J. and Harris, P.D. (2007). The biology of gyrodactylid monogeneans: the 'Russian-doll killers'. Advances in Parasitology 64, 161-376.

Barson, N. J., Cable, J. and van Oosterhout, C. (2009). Population genetic analysis of microsatellite variation of guppies (Poecilia reticulata) in Trinidad and Tobago: evidence for a dynamic source-sink metapopulation structure, founder events and population bottlenecks. Fournal of Evolutionary Biology 22, 485-497.

Burgess, P., McMahon, S. and Price, D. J. (2005). Conservation of Trinidad populations of Poecilia reticulata Peters, 1859 (Poeciliidae). In Viviparous Fishes (ed. Grier, H. and Uribe, M. C.), pp. 426-434. New Life Publications, Homestead, FL, USA.

Cable, J. (2011). Poeciliid Parasites. In Ecology and Evolution of Poeciliid Fishes. (ed. Evans, J. P., Pilastro, A. and Schlupp, I.), pp. 82-94. Chicago University Press, Chicago IL, USA.

Cable, J. and Harris, P. D. (2002). Gyrodactylid developmental biology: historical review, current status and future trends. International Fournal for Parasitology 32, 255-280.

Cable, J. and van Oosterhout, C. (2007). The impact of parasites on the life history evolution of guppies (Poecilia reticulata): the effects of host size on parasite virulence. International fournal for Parasitology 37, 1449-1458. Coltrain, J. B., Harris, J. M., Cerling, T. E., Ehleringer, J. R., Dearing, M. D., Ward, J. and Allen, J. (2004). Rancho La Brea stable 
isotope biogeochemistry and its implications for the palaeoecology of late Pleistocene, coastal Southern California. Palaeogeography, Paleoclimatology and Palaeoecology 205, 199-219.

Decaestecker, E., Gaba, S., Raeymaekers, J. A. M., Stocks, R., van Kerckhoven, L., Ebert, D. and De Meester, L. (2007). Host-parasite 'Red Queen' dynamics archived in pond sediment. Nature, London 450, 870-873.

Dybdahl, M. F. and Lively, C. M. (1998). Host-Parasite Coevolution: Evidence for Rare Advantage and Time-Lagged Selection in a Natural Population. Evolution 52, 1057-1066.

Dunson, W. A., Swarts, F. and Silversti, M. (1977). Exceptional tolerance of low pH of some tropical blackwater fish. Fournal of Experimental Zoology 201, 157-162.

Fraser, B. A. and Neff, B.D. (2010). Parasite mediated homogenizing selection at the MHC in guppies. Genetica 138, 273-278.

Harris, P. D., Cable, J., Tinsley, R. C. and Lazarus, C. M. (1999). Combined ribosomal DNA and morphological analysis of individual gyrodactylid monogeneans. Fournal of Parasitology 85, 188-191.

Kadavy, D. R., Plantz, B., Shaw, C. A., Myatt, J., Kokjohn, T. A. and Nickerson, K. W. (1999). Microbiology of the oil fly, Helaeomyia petrolei. Applied and Environmental Microbiology 65, 1477-1482.

Khan, R. A. (1990). Parasitism in marine fish after chronic exposure to petroleum hydrocarbons in the laboratory and to the Exxon Valdez oil spill. Bulletin of Environmental Contamination and Toxicology 44, 759-763.

Kahn, R. A. and Kiceniuk, J. W. (1988). Effect of petroleum aromatic hydrocarbons on monogeneids parasitizing Atlantic cod, Gadus morhua L. Bulletin of Environmental Contamination and Toxicology 41, 94-100.

Lawrence, N.S., Davis, J. and Compton, R. G. (2000). Analytical strategies for the detection of sulfide: a review. Talanta 52, 711-784.

Lindström, K. M., Foufopoulos, J., Pärn, H. and Wikelski, M. (2004) Immunological investments reflect parasite abundance in island populations of Darwin's finches. Proceedings of the Royal Society of London, B 271, 1513-1519.

Liu, H. and Stiling, P. (2006). Testing the enemy release hypothesis: a review and meta-analysis. Biological Invasions 8, 1535-1545.

Lively, C. M. (1987). Evidence from a New-Zealand snail for the maintenance of sex by parasitism. Nature, London 328, 519-521.

Lively, C. M. and Jokela, J. (2002). Temporal and spatial distributions of parasites and sex in a freshwater snail. Evolutionary Ecology Research 4, 219-226.

Magurran, A. E. (2005). Evolutionary Ecology: The Trinidadian Guppy. Oxford Series in Ecology and Evolution, Oxford, UK

Marković, S., Marković, Z., McCrindle, R. I. and Simonović, B. R. (2007). Kinetics of extraction of coal-tar pitch components with supercritical carbon dioxide. Chemical Papers 61, 46-50.

Martin, C. H. and Johnson, S. (2007). A field test of the Hamilton-Zuk hypothesis in the Trinidadian guppy (Poecilia reticulata). Behavioral Ecology and Sociobiology 61, 1897-1909.

McMullan, M. (2010). Host-parasite co-evolution and genetic variation at the Major Histocompatibility Complex in the Trinidadian guppy (Poecilia reticulata). Ph.D. thesis, University of Hull, UK.

Pan, Z. and Raftery, D. (2007). Comparing and combining NMR spectroscopy and mass spectrometry in metabolomics. Analytical and Bioanalytical Chemistry 387, 525-527.

Paterson, S., Vogwill, R., Buckling, A., Benmayor, R., Spiers, A. J., Thomson, N. R., Quail, M., Smith, F., Walker, D., Libberton, B., Fenton, A., Hall, N. and Brockhurst, M. A. (2010). Antagonistic coevolution accelerates molecular evolution. Nature, London 464, 275-278.
Peckham, S. F. (1895). V. - On the Pitch Lake of Trinidad. Geological Magazine 2, 452-458.

Ponnamperuma, C. and Pering, K. L. (1967). Aliphatic and alicyclic hydrocarbons isolated from Trinidad Lake asphalt. Geochimica et Cosmochimica Acta 31, 1350-1354.

Price, P. W. (1980). Evolutionary Biology of Parasites. Princeton University Press, Princeton, NJ, USA

R Development Core Team (2011). R: A Language and Environment for Statistical Computing. R Foundation for Statistical Computing. Vienna, Austria. URL: http://www.r-project.org.

Schelkle, B., Doetjes, R. and Cable, J. (2010). The salt myth revealed: treatment of gyrodactylid infections on ornamental guppies, Poecilia reticulata. Aquaculture 311, 74-79.

Schelkle, B., Paladini, G., Shinn, A.P., King, S., Johnson, M., van Oosterhout, C., Mohammed, R.S. and Cable, J. (2011). Ieredactylus rivuli $\mathrm{n}$. gen. et $\mathrm{sp}$. (Monogenea: Gyrodactylidae) from Rivulus hartii (Cyprinodontiformes: Rivulidae) in Trinidad. Acta Parasitologica 56, 360-370.

Schelkle, B., Shinn, A. P., Peeler, E. and Cable, J. (2009). Treatment of gyrodactylid infections in fish. Diseases of Aquatic Organisms 86, 65-75.

Schulze-Makuch, D., Haque, S., Resendes de Sousa Antonio, M., Ali, D., Hosein, R., Song, Y. C., Yang, J., Zaikova, E., Beckles, D. M., Guinan, E., Lehto, H. J. and Hallam, S. J. (2010). Microbial Life in a Liquid Asphalt Desert. arXiv:1004-2047v1 [q-bio.GN]. Available online: http://arxiv.org/abs/1004-2047v1, accessed: 11 April 2012.

Scott, M. E. and Anderson, R. M. (1984). The population dynamics of Gyrodactylus bullatarudis (Monogenea) within laboratory populations of the fish host Poecilia reticulata. Parasitology 89, 159-194.

Shephard, K. L. (1994). Functions for fish mucus. Reviews in Fish Biology and Fisheries 4, 401-429.

Tezuka, A., Yamamoto, H., Yokoyama, J., van Oosterhout, C. and Kawata, M. (2011) The MC1R gene in the guppy (Poecilia reticulata): Genotypic and phenotypic polymorphisms. BMC Research Notes 4, 31.

Tobler, M., Schlupp, I., García de León, F. J., Glaubrecht, M. and Plath, M. (2007). Extreme habitats as refuge from parasite infections? Evidence from an extremophile fish. Acta Oecologica 31, 270-275. van Oosterhout, C., Harris, P. D. and Cable, J. (2003). Marked variation in parasite resistance between two wild populations of the Trinidadian guppy, Poecilia reticulata (Pisces: Poeciliidae). Biological Fournal of the Linnean Society 79, 645-651.

van Oosterhout, C., Mohammed, R. S., Hansen, H., Archard, G. A., McMullan, M., Weese, D. J. and Cable, J. (2007). Selection by parasites in spate conditions in a wild Trinidadian guppies (Poecilia reticulata). International Fournal for Parasitology 37, 805-812.

Willing, E. M., Bentzen, P., Hoffmann, M., van Oosterhout, C., Cable, J., Breden, F., Weigel, D. and Dreyer, C. (2010). Genome-wide single nucleotide polymorphisms reveal population history and adaptive divergence in wild guppies. Molecular Ecology 19, 968-984.

Woolhouse, M. E. J., Webster, J. P., Domingo, E., Charlesworth, B. and Levin, B. R. (2002). Biological and biomedical implications of the coevolution of pathogens and their hosts. Nature Genetics 32, 569-577.

World Health Organization Concise International Chemical Assessment Documents (2005). Asphalt (Bitumen). Available online: http://www.who.int/ipcs/publications/cicad/cicad59_rev_1.pdf. Accessed: 11 April 2012 